\title{
Bile Acid Transporters Are Expressed and Heterogeneously Distributed in Rat Bile Ducts
}

\author{
Zhu-lin Luo ${ }^{1}$, Long Cheng ${ }^{1}$, Tao Wang ${ }^{1}$, Li-jun Tang ${ }^{1}$, Fu-zhou Tian ${ }^{1}$, Ke Xiang $^{1}$, and Lin Cui ${ }^{2}$ \\ Departments of ${ }^{1}$ General Surgery and ${ }^{2}$ Orthopedics, Chengdu Military General Hospital, Chengdu, China
}

Background/Aims: Cholangiocytes are capable of reabsorbing bile salts from bile, but the pathophysiological significance of this process is unclear. To this end, we detected the expression and distribution of bile acid transport proteins in cholangiocytes from normal rat liver and analyzed the possible pathophysiological significance. Methods: Bile duct tissues of Sprague-Dawley rats were isolated by enzymatic digestion and mechanical isolation, and then divided into large and small bile duct tissues. Immunohistochemistry, real-time polymerase chain reaction and Western blotting were used to determine the expression of the apical sodium-dependent bile acid transporter (ASBT), ileal bile acid binding protein (IBABP), and basolateral organic solute transporter $\alpha$ (Ost $\alpha$ ) in the biliary tract system of rats. Differences in the expression and distribution of these proteins were analyzed. Results: In cholangiocytes, ASBT and IBABP were mainly expressed in cholangiocytes of the large bile ducts, in which the expression of both was significantly higher than that in the small ducts $(p<0.05)$. Ost $\alpha$ was simultaneously expressed in cholangiocytes of both the large and small bile ducts, showing no significant difference in expression between the two groups of bile ducts ( $p>0.05)$. Conclusions: Bile acid transporters are expressed and heterogeneously distributed in rat bile ducts, indicating that bile acid reabsorption by cholangiocytes might mainly occur in the large bile ducts. These findings may help explore the physiology of bile ducts and the pathogenesis of various cholangiopathies. (Gut Liver 2019;13:569-575)

Key Words: Cholangiocyte; Bile acid transporter; Heterogeneity; Cholangiopathies

\section{INTRODUCTION}

Cholangiocytes are the epithelial cells that line the intrahepatic biliary tree, a network of interconnecting ducts of increasing diameter from the duct of Hering to the extrahepatic bile ducts. ${ }^{1,2}$ Cholangiocytes determine the final composition and volume of bile through a number of reabsorptive/secretory events regulated by various hormones, peptides, and neurotransmitters. ${ }^{2}$ Moreover, cholangiocytes are structurally and functionally heterogeneous in biliary tree. ${ }^{3,4}$ In structure, cholangiocytes are divided into small and large cholangiocytes based on the cellular morphological and phenotypic characteristics. ${ }^{3}$ Small $(<15 \mu \mathrm{m})$ and large $(\geq 15 \mu \mathrm{m})$ bile ducts are lined by small and large cholangiocytes, respectively. ${ }^{4}$ With regards to cellular structure, small cholangiocytes are cuboidal in shape and have a high nucleus/cytoplasm ratio, while large cholangiocytes are more columnar and have a small nucleus/cytoplasm ratio. ${ }^{2,5} \mathrm{Be}-$ sides, the large cholangiocytes have cilia that act as chemo- and mechano-sensors in the bile ducts. ${ }^{6}$ In function, each type has important differences in secretory responses to bio-molecules (e.g., gastrointestinal hormones and peptides) and proliferative and apoptosis activities in response to injury or toxins. ${ }^{3,4}$ Moreover, cholangiocytes have been considered as the specific treatment target of cholangiopathies. ${ }^{1,2}$ Hence, elucidating the precise molecular mechanisms of cholangiocytes can help understand bile duct physiology and explore the pathogenesis of a variety of bile duct diseases, providing a theoretical basis to guide clinical diagnosis and treatment.

Bile acids are synthesized in the liver from cholesterol and are specific important organic components of bile. ${ }^{7}$ Accumulated studies suggest that bile acids absorbed by cholangiocytes recycle via the peribiliary plexus back to hepatocytes for re-secretion into bile. ${ }^{7-9}$ Bile acids from bile can first be transported into

\footnotetext{
Correspondence to: Long Cheng ${ }^{\mathrm{a}}$ and Tao Wang ${ }^{\mathrm{b}}$

Department of General Surgery, Chengdu Military General Hospital, No.270, Rongdu Avenue, Chengdu 610083, China

Tel: +86-28-86570211, Fax: +86-28-86570211, E-mail: ${ }^{\mathrm{a}}$ longchen_med@126.com and ${ }^{\mathrm{b}}$ watopo@163.com

Received on June 8, 2018. Revised on November 22, 2018. Accepted on December 3, 2018. Published online May 30, 2019

pISSN 1976-2283 eISSN 2005-1212 https://doi.org/10.5009/gnl18265

Zhu-lin Luo and Long Cheng contributed equally to this work as first authors.

@. This is an Open Access article distributed under the terms of the Creative Commons Attribution Non-Commercial License (http://creativecommons.org/licenses/by-nc/4.0) which permits unrestricted non-commercial use, distribution, and reproduction in any medium, provided the original work is properly cited.
} 
cholangiocytes through the apical sodium-dependent bile acid transporter (ASBT). ${ }^{9,10}$ After entering cholangiocytes, bile acids bind to the ileal bile acid binding protein (IBABP). ${ }^{10}$ Alternatively, bile acids can be transported into the peribiliary vascular plexus and enter the portal system through basolateral heteromeric organic solute transporter $\alpha$ (Ost $\alpha)$ and $\beta(0 S t \beta))^{9,10}$ This recycling of bile acids between cholangiocytes and hepatocytes is known as the cholehepatic shunt pathway, which is conductive to the adaptation to chronic cholestasis caused by extrahepatic obstruction and to overall hepatobiliary transport of bile acids. ${ }^{9}$ Moreover, bile acids play a critical role in regulating the proliferation, differentiation, survival, and secretion of cholangiocytes. ${ }^{8}$ Thus, excess reabsorption, deficiency, or transport imbalance of bile acids by cholangiocytes is likely to cause pathophysiological changes in these cells. ${ }^{8}$ The interaction between bile acids and cholangiocytes is regarded as a potential target for various cholangiopathies therapy, and has been widely studied. ${ }^{8,9}$ However, from the perspective of cholangiocytes re-absorbed bile acids, the heterogeneous distribution of bile salt transporters in small and large cholangiocytes has not been elucidated.

This study focused on the detection and analysis of expression differences in bile acid transporters between small and large cholangiocytes, including ASBT, IBABP, and Ost $\alpha$. The results will form the theoretical and experimental basis for investigating the role of heterogeneity in bile acids reabsorption by cholangiocytes during the development of bile duct diseases.

\section{MATERIALS AND METHODS}

\section{Experimental animals}

Grade II male Sprague-Dawley rats, aged 6 to 8 weeks old and weighing 200 to 250 g, were purchased from the Experimental Animal Center of Daping Hospital, Third Military Medical University. The rats were reared in a thermostat-regulated clean environment and maintained with a circadian rhythm of 12-hour light/12-hour dark. The work was approved by the
Animal Use and Care Committees of Chengdu Military General Hospital (Animal Welfare Assurance number: A2017-106).

\section{Isolation of large and small bile ducts}

Bile duct tissue was isolated using the intrahepatic bile duct separation method as previously described. ${ }^{11}$ After SpragueDawley rats were anesthetized (pentobarbital, $50 \mathrm{mg} / \mathrm{kg}$ ), the abdomen was entered layer by layer through an upper abdominal transverse incision. Portal vein catheterization was performed using a 22-gauge detained needle. After 5 minutes of continuous perfusion, D-Hank's solution was replaced with D-Hank's solution containing 0.05\% type IV collagenase for another 10 minutes of continuous perfusion. Then, the liver was taken and placed in a cholangiocyte growth medium (Dulbecco's modified Eagle's medium [DMEM]/F12=1:1 basal medium) supplemented with 10\% fetal bovine serum, $100 \mathrm{U} / \mathrm{L}$ penicillin-streptomycin double-antibiotic, $400 \mu \mathrm{g} / \mathrm{L}$ dexamethasone, $10 \mathrm{~g} / \mathrm{L}$ insulin, and $25 \mu \mathrm{g} / \mathrm{L}$ epidermal growth factor. Liver parenchyma and hepatic veins were removed by blunt dissection, and a portion of the intrahepatic biliary tree was retained. The biliary tree was divided into two parts (large and small bile ducts) under the surgical microscope based on the morphological analysis. Small bile duct has a diameter less than $15 \mu \mathrm{m}$ and is lined by four (or less) cholangiocytes that are cuboidal in shape. ${ }^{2,12}$ However, the diameter of large bile duct is more than $15 \mu \mathrm{m}$, and the large cholangiocytes are usually in columnar shape and have cilia as chemo- and mechano-sensors., ${ }^{2,6}$ Additionally, with the ends of third-grade bile duct branches as the boundary, small bile duct mostly located in the proximal part of the boundary, while the large bile duct mainly assembled in the distal part (Fig. 1). The bile duct tissues were stored in liquid nitrogen, preparing for the protein and RNA extraction.

\section{Immunohistochemical assay for cholangiocyte expres- sion of bile salt transport proteins}

ASBT, IBABP, and Ost $\alpha$ expression in rat bile ducts was de-
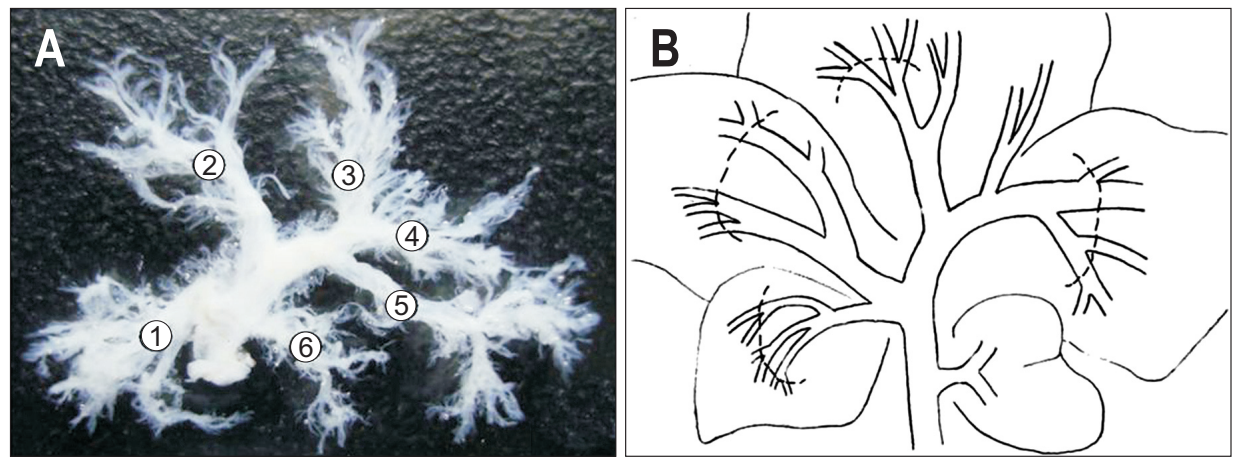

Fig. 1. Isolation of large and small bile ducts. (A) Diagram of rat biliary tree: the complete biliary tree was obtained by collagenase perfusiondigestion and mechanical isolation. The complete biliary system includes the following branch systems: (1) caudate lobe, (2) right lobe, (3) median lobe, (4) left median lobe, (5) left lateral lobe, and (6) discoid process. (B) Schematic of large and small rat bile duct isolation; under the surgical microscope, the bile duct tissue was divided into two parts at the ends of third-grade bile duct branches (dotted line): the portion proximal to the porta hepatis mainly contained large bile ducts, and the surrounding portion mainly contained small bile ducts. 
tected by immunohistochemical (IHC) assay. The tissues were successively treated with formaldehyde fixation, ethanol dehydration, paraffin embedding, cutting into slices, dewaxing and antigen retrieval. Each section was incubated with primary antibodies against ASBT (1:200; Santa Cruz Biotechnology Inc., Santa Cruz, CA, USA), IBABP (1:200; Santa Cruz Biotechnology Inc.), and Ost $\alpha$ (1:100; Abcam, Cambridge, MA, USA) overnight at $4^{\circ} \mathrm{C}$. For the negative control, the primary antibodies were substituted with phosphate-buffered saline (PBS). Then, each section was washed with PBS and further cultured with the secondary antibody for 30 minutes. The samples were stained using a streptavidin-biotin complex IHC staining kit, and then visualized by optical microscope. The assay was repeated for three times. The relative protein expression was quantified by Image-Pro Plus version 6.0 software (Media Cybernetics, Rockville, MD, USA) and defined as follows: density mean=density sum/area sum.

\section{RNA extraction quantitative and real-time PCR (qRT-PCR) assay}

Total RNA was extracted using RNAiso Plus (Takara, Kyoto, Japan) based on the manufacturer's instructions. For reverse transcription, cDNA was prepared using a Primscript ${ }^{\mathrm{TM}}$ (Takara) RT reagent kit according to the manufacturer's protocol. Realtime polymerase chain reaction (PCR) was performed using a SYBR Premix Ex $\mathrm{Taq}^{\mathrm{TM}}$ (Takara) III kit. The reaction procedures were listed as follows: $95^{\circ} \mathrm{C}$ for 5 minutes, 40 cycles of $92^{\circ} \mathrm{C}$ for 30 seconds, $60^{\circ} \mathrm{C}$ for 40 seconds, and $72^{\circ} \mathrm{C}$ for 1 minutes. The primers were purchased from Sangon Biotech (Shanghai, China), and their sequences and product sizes are shown in Table 1 . The relative expression was evaluated and normalized using the $2^{-\Delta \Delta \mathrm{Ct}}$ method relative to $\beta$-actin. Then, the amplification PCR products were analyzed by electrophoresis in a $2 \%$ agarose gel. Each sample was repeated for three times.

\section{Protein extraction and Western blot}

Biliary proteins were extracted as previously described. ${ }^{11}$ Protein extracts were stored at $-80^{\circ} \mathrm{C}$ before analysis. Protein con- centration was determined using a bicinchoninic acid (BCA) assay kit. Samples were loaded on an 8\% sodium dodecyl sulfatepolyacrylamide gel electrophoresis (SDS-PAGE) gel (50 $\mu \mathrm{g}$ per well) for electrophoresis ( 2 hours at $20 \mathrm{~V}$ followed by 3 hours at $80 \mathrm{~V}$ ). The samples were transferred to polyvinylidene fluoride (PVDF) membranes at $200 \mathrm{~mA}$ for 2 hours. After blocking overnight with $5 \%$ skim milk, the membranes were incubated at room temperature with primary antibodies (ASBT, 1:500; IB$\mathrm{ABP}, 1: 500$; and 0st $\alpha, 1: 1,000)$ overnight. The membranes were washed with TBST buffer and then incubated with secondary antibodies for 2 hours. Then, luminescence reagent was applied for development and X film imaging. The membranes were imaged by ECL Detection System (Bio-Rad, Hercules, CA, USA). Besides, gray scale analysis was performed using Quantity One (Bio-Rad. USA). The procedures were repeated for three times.

\section{Statistical analysis}

All of the data were statistically analyzed using Statistical Package for Social Science version 17.0 (SPSS INC., Chicago, IL, USA). Continuous data are expressed as the mean \pm standard deviation. The significant difference between two groups was assessed using Student t-tests. Differences with p-values less than 0.05 were considered statistically significant.

\section{RESULTS}

\section{ASBT expression in bile ducts of normal rats}

IHC assay, qRT-PCR and Western blot were used to determine the expression of ASBT in bile ducts of normal rats. As shown in Fig. 2A, IHC analysis showed that ASBT was expressed in the apical membrane of cholangiocytes, mainly in the large bile ducts. With decreasing bile duct diameter, ASBT expression level gradually decreased, and there was almost no ASBT expression in the small periportal bile ducts (Fig. 2B). Based on the images of IHC assay, ASBT expression was semi-quantified by Image-Pro Plus v 6.0. The result showed that the mean density of ASBT in the large bile ducts was higher compared with the small bile ducts $(\mathrm{p}<0.05)$ (Fig. $2 \mathrm{C})$. qRT-PCR data showed that

Table 1. Primer Sequences and Product Sizes

\begin{tabular}{|c|c|c|c|}
\hline Target gene & Primer & Temperature $\left({ }^{\circ} \mathrm{C}\right)$ & Product (bp) \\
\hline \multirow[t]{2}{*}{ ASBT } & (Forward) 5'-CAGTTTGGAATCATGCCTCTC-3' & 56 & 207 \\
\hline & (Reverse) 5'-AAGGGGCATCATTCCAAGAGC-3' & & \\
\hline \multirow[t]{2}{*}{ IBABP } & (Forward) 5'-CTTCACCTGGTCCCAGTCT-3' & 55 & 187 \\
\hline & (Reverse) 5'-CAACTTGTCACCCACGAC-3' & & \\
\hline \multirow[t]{2}{*}{ Ost $\alpha$} & (Forward) 5'-CCCTCATACTTACCAGGAAGAAGCTAC-3' & 58 & 109 \\
\hline & (Reverse) 5'-CCATCAGGAATGAGAAACAGGC-3' & & \\
\hline \multirow[t]{2}{*}{$\beta$-Actin } & (Forward) 5'-ATATCGCTGCGCTCGTCGTC-3' & 57 & 174 \\
\hline & (Reverse) 5'-TCTTGCTCTGGGCCTCGTC-3' & & \\
\hline
\end{tabular}

ASBT, apical sodium-dependent bile acid transporter; IBABP, ileal bile acid binding protein; Ost $\alpha$, basolateral organic solute transporter $\alpha$. 

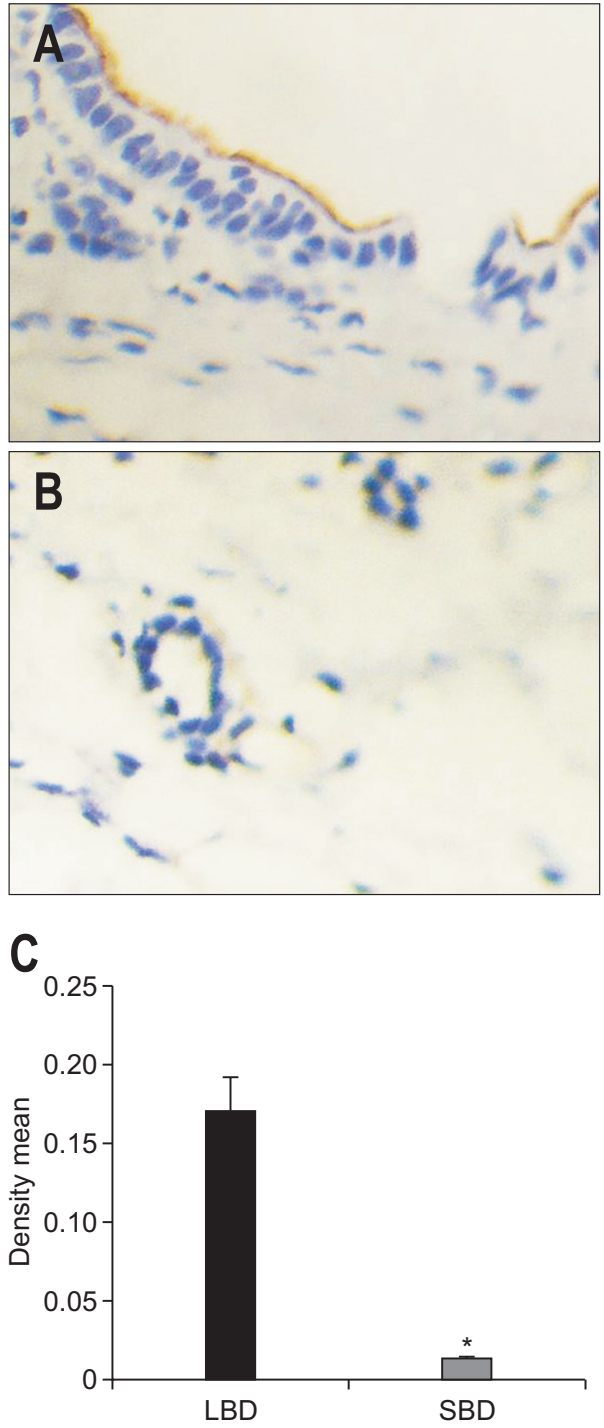

D

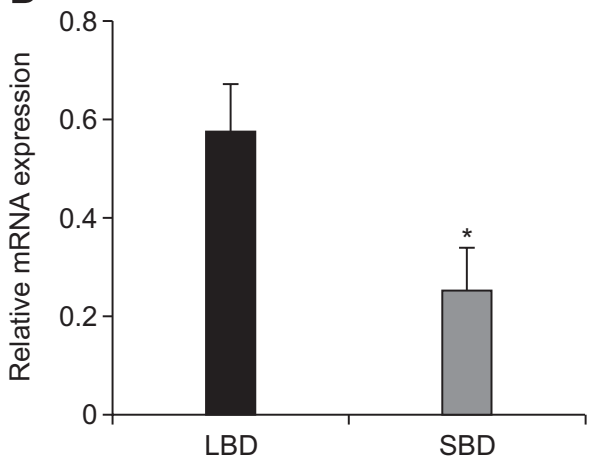

E

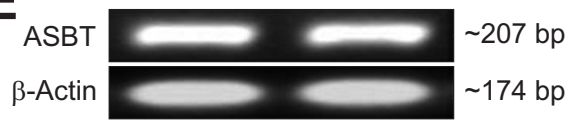

$\mathbf{F}$

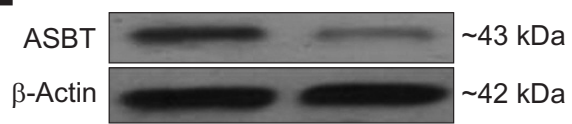

\section{G}

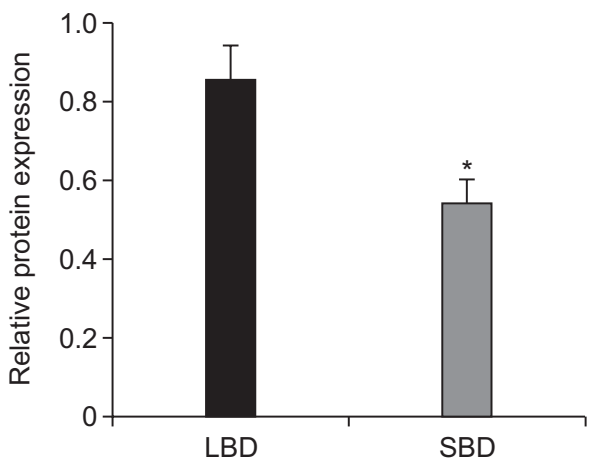

Fig. 2. Differences in apical sodiumdependent bile acid transporter (ASBT) expression in small bile ducts (SBDs) and large bile ducts (LBDs). (A) Immunohistochemical (IHC) showed ASBT expression in the apical membrane of cholangiocytes (x400). (B) With decreasing bile duct diameter, the ASBT expression level gradually decreased, and almost no ASBT expression was observed in the small periportal bile ducts (IHC, $\times 400$ ). (C) Based on the IHC images, quantification of ASBT expression was performed by Image-Pro Plus v 6.0. (D) Quantitative real-time polymerase chain reaction (qRT-PCR) showed significantly higher ASBT mRNA expression level in the LBDs than in the SBDs. (E) After PCR analysis, the amplified PCR products were identified by electrophoresis, and (F) Western blotting results also showed a significantly higher ASBT protein expression level in the LBDs than in the SBDs. (G) Quantification of the ASBT protein band was performed and normalized relative to the expression level of $\beta$-actin. ${ }^{*} \mathrm{p}<0.05$ : SBDs versus LBDs. the relative ASBT mRNA expression levels were $0.59 \pm 0.10$ and $0.26 \pm 0.07$ in the large and small bile duct tissues, respectively (Fig. 2D). Subsequently, electrophoretic analysis identified that the amplified PCR products in two groups were ASBT DNA (Fig. 2E). Western blot results indicated that the relative expression levels of ASBT protein were $0.84 \pm 0.21$ and $0.49 \pm 0.18$ in the large and small bile duct tissues, respectively (Fig. 2F and G). Statistical analysis suggested that ASBT was significantly highly expressed at both the mRNA and protein levels in the large bile ducts compared with the small bile ducts $(\mathrm{p}<0.05)$.

\section{IBABP expression in bile ducts of normal rats}

The expression level of IBABP in bile ducts of normal rats was detected by IHC assay, qRT-PCR and Western blot. IHC data showed that IBABP was expressed in the cytoplasm of cholangiocytes, mainly in the large bile ducts (Fig. 3A). With decreasing bile duct diameter, IBABP expression level gradually decreased, and there was almost no IBABP expression in the small periportal bile ducts (Fig. 3B). The mean density was significantly higher in the large bile ducts in compared to the small bile ducts $(\mathrm{p}<0.05)$ (Fig. $3 \mathrm{C})$. The data of qRT-PCR revealed that the relative expression levels of IBABP mRNA in the large and small bile duct tissue were $0.66 \pm 0.12$ and $0.20 \pm 0.06$, respectively (Fig. 3D). Then, the amplified PCR products in two groups were indeed IBABP DNA, which was identified by electrophoretic analysis (Fig. 3E). As shown in Fig. 3F and G, Western blot results indicated that the relative expression levels of IBABP protein were $0.56 \pm 0.11$ and $0.17 \pm 0.08$ in the large and small bile duct tissues, respectively. According to statistical analysis, IBABP was significantly highly expressed in the large bile duct tissue compared with the small bile duct tissue at both the mRNA and protein levels $(\mathrm{p}<0.05)$.

\section{Ost $\alpha$ expression in bile ducts of normal rats}

To determine the expression of Ost $\alpha$ in bile ducts of normal rats, IHC assay, qRT-PCR and Western blot were used. IHC assay results showed that Ost $\alpha$ was expressed in the basolateral membrane of cholangiocytes, with no significant expression differ- 

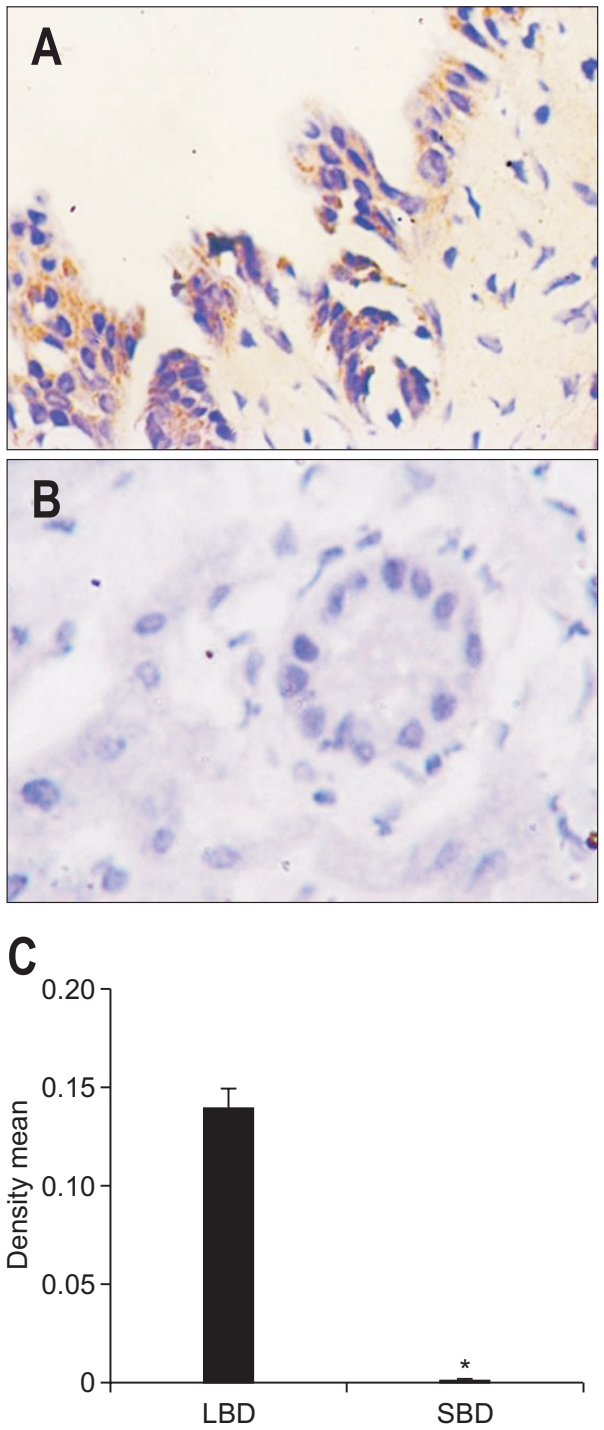

D

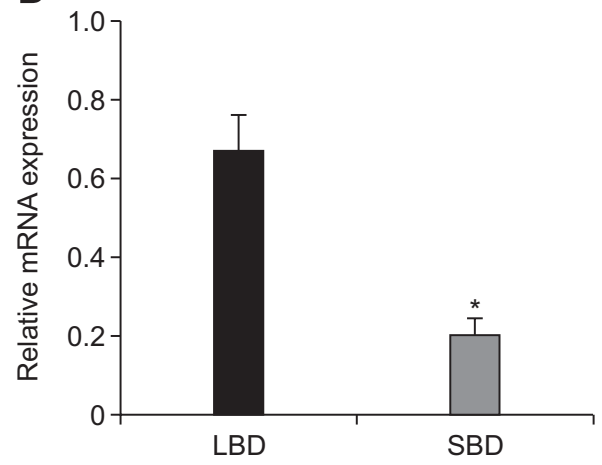

$E$

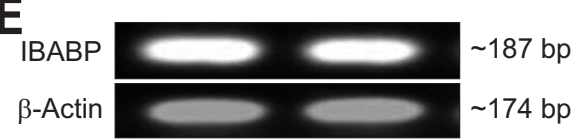

$\mathbf{F}$

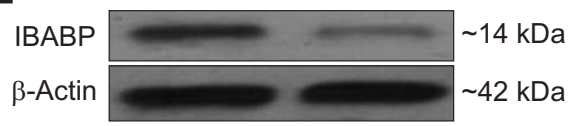

G

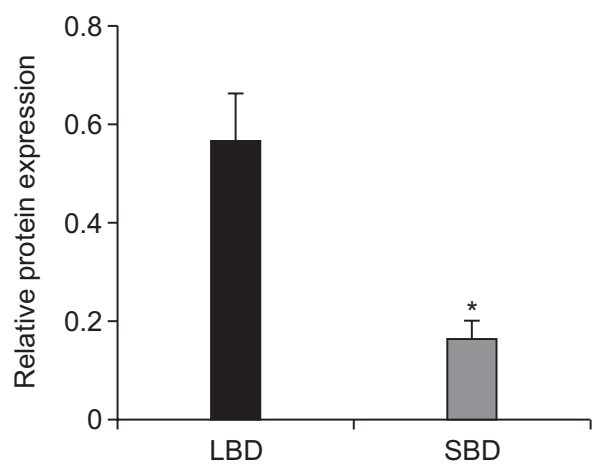

Fig. 3. Difference in ileal bile acid binding protein (IBABP) expression in small bile ducts (SBDs) and large bile ducts (LBDs). (A) Immunohistochemical (IHC) showed IBABP expression in the cytoplasm of cholangiocytes $(\times 400)$. (B) With decreasing bile duct diameter, the IBABP expression level decreased gradually, and almost no IBABP expression was observed in the small periportal bile ducts (IHC, $\times 400)$. (C) Based on the IHC images, quantification of IBABP expression was performed by Image-Pro Plus v 6.0. (D) Quantitative real-time polymerase chain reaction (qRT-PCR) showed significantly higher IBABP mRNA expression level in the LBDs than in the SBDs. (E) After PCR analysis, the lengths of the amplified PCR products were verified by electrophoresis. (F) Western blotting results also showed a significantly higher IBABP protein expression level in the LBDs than in the SBDs. (G) Quantification of the IBABP protein band was calculated and normalized relative to the expression level of $\beta$-actin. ${ }^{*} \mathrm{p}<0.05$ : SBDs versus LBDs. ence between the large and small bile ducts. Additionally, Osta was expressed on the sinusoidal surface of hepatocytes (Fig. 4A and B). The mean density of Ost $\alpha$ had no significant difference between the large and small bile ducts ( $p=0.544$ ) (Fig. 4C). qRTPCR analysis suggested that the relative Ost $\alpha$ mRNA expression levels were $0.39 \pm 0.05$ and $0.52 \pm 0.06$ in the large and small bile duct tissues, respectively (Fig. 4D). Subsequently, electrophoresis confirmed that the amplified PCR products in two groups were Ost $\alpha$ DNA indeed (Fig. 4E). Western blot indicated that the relative 0st $\alpha$ protein expression levels were $0.72 \pm 0.12$ and $0.83 \pm 0.21$ in the large and small bile duct tissues, respectively (Fig. 4F and G). Statistical analysis showed no significant difference between the large and small bile duct tissues at Ost $\alpha$ mRNA or protein expression level ( $p>0.05$ ).

\section{DISCUSSION}

This study focused on the expression differences of bile salt transporters in small and large bile ducts. Bile salt transport- ers (i.e., ASBT and IBABP) were mainly expressed in large bile ducts as compared to small bile ducts, which indicated bile acid reabsorption of cholangiocytes occurred mostly in the large bile ducts. These findings may help understand the pathogenesis of various bile duct diseases.

Small and large cholangiocytes have important differences in the biliary tree of rodents and humans. ${ }^{3,4}$ It has been reported that only large cholangiocytes are cyclic adenosine 3', 5'-monophosphate (cAMP) responsive and express the chloride bicarbonate anion exchanger $2\left(\mathrm{Cl}^{-} / \mathrm{HCO}^{3-} \mathrm{AE} 2\right)$, cystic fibrosis transmembrane conductance regulator, and secretin receptors. ${ }^{13}$ Interleukin 33 (IL-33), a member of the IL-1 cytokine family, may play a critical role in promoting the neoplastic transformation of cholangiocytes, whereas its effects seem to be restricted to the large bile ducts. ${ }^{14}$ Alpini et al. ${ }^{15}$ showed that nuclear factor of activated T cells 2 (NFAT2), NFAT4 and $\mathrm{Ca}^{2+}$-dependent transcription factors were predominantly expressed in small cholangiocytes. Hence, the differences in small and large cholangiocytes can effectively influence the bile duct physiology 

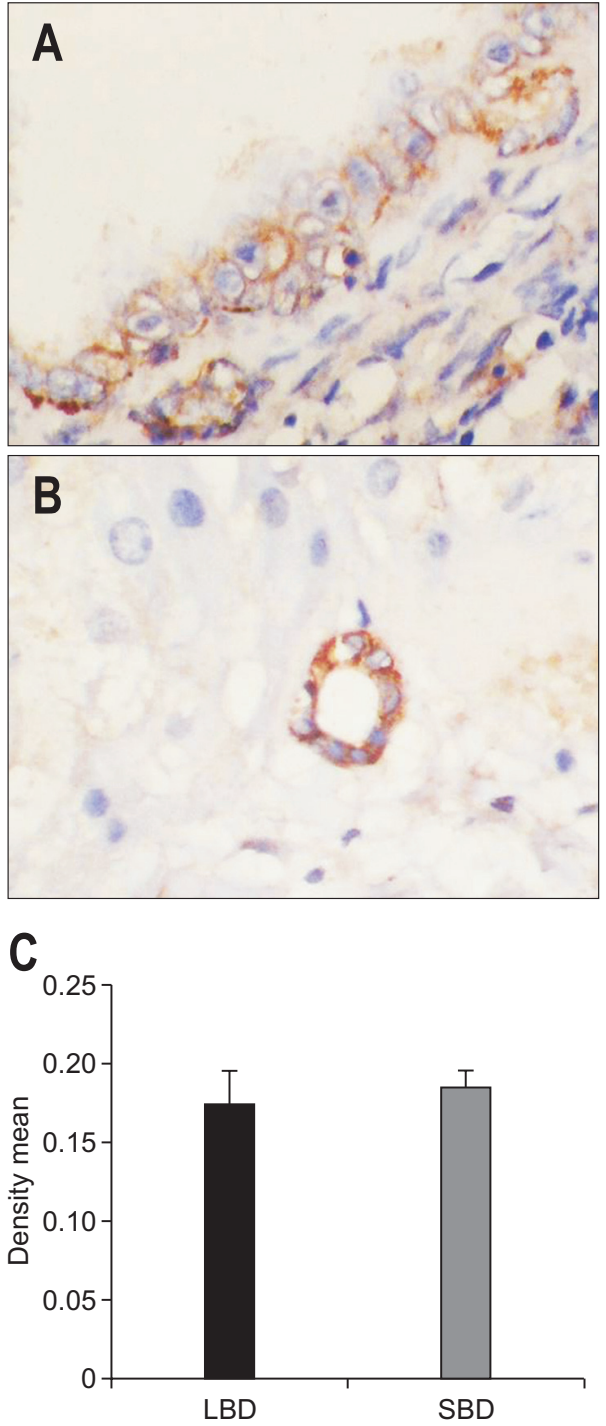

D

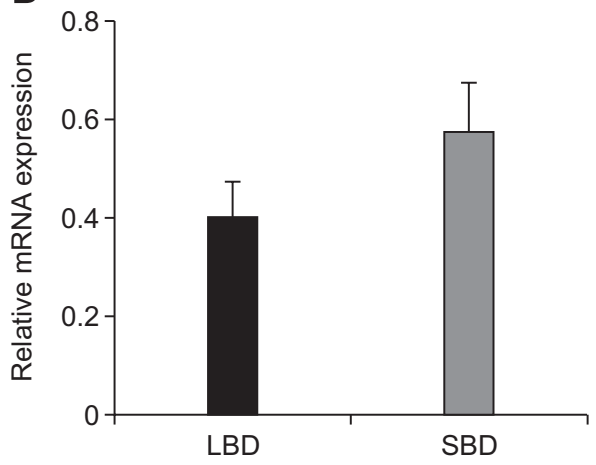

E

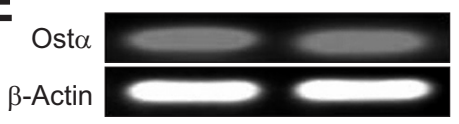

$\sim 109 \mathrm{bp}$

$\sim 174 \mathrm{bp}$

\section{$\mathbf{F}$}

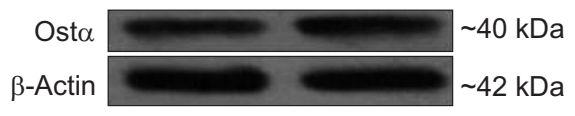

\section{G}

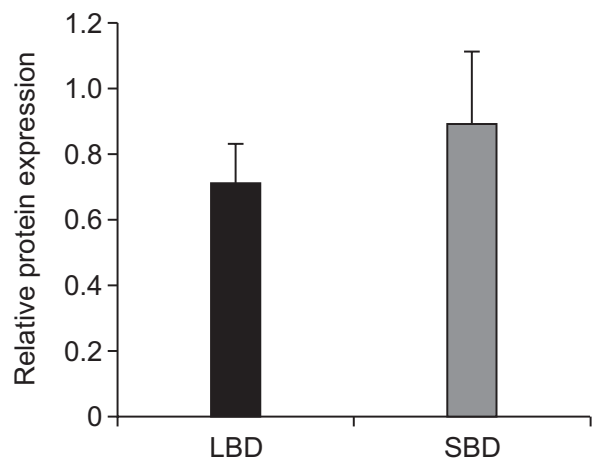

Fig. 4. Difference in organic solute transporter $\alpha(0$ st $\alpha)$ expression in small bile ducts (SBDs) and large bile ducts (LBDs). (A) Immunohistochemical (IHC) showed Osta expression in the basolateral membrane of cholangiocytes $(\times 400)$. (B) Ost $\alpha$ was also expressed in cholangiocytes of the SBDs, mainly in the basolateral membrane, and showed no significant difference in expression from the LBDs (IHC, $\times 400)$. (C) Based on the IHC images, quantification of Osta expression was performed by Image-Pro Plus v 6.0. (D) Quantitative real-time polymerase chain reaction (qRT-PCR) showed no significant difference in Ost $\alpha$ mRNA expression in the LBDs and SBDs. (E) After PCR analysis, electrophoresis was used to determine the length of the amplified PCR products. (F) Western blotting results also showed no significant difference in the Osta protein expression level in the LBDs and SBDs. (G) Quantification of the Ost $\alpha$ protein band was evaluated and normalized relative to the expression level of $\beta$-actin. and various cholangiopathies pathogenesis. Although heterogeneity in cholangiocyte structure and function has been extensively studied, the functional heterogeneity in bile acids reabsorption by cholangiocytes is hardly reported. Bile acids are known to be involved in multiple functions in liver cells, mainly cholangiocytes and hepatocytes, and in extrahepatic tissues. ${ }^{8}$ For instance, bile acids play an important role in regulating the cell proliferation, differentiation, survival and secretion. ${ }^{8,16}$ If bile acid homeostasis is disturbed, several cholangiopathies will happen. Increased intrahepatic accumulation of bile acid can cause cholestasis, polycystic liver diseases, and cholangiocarcinoma. ${ }^{16,17}$ Moreover, bile acid transporters in cholangiocytes are critical for maintaining bile acid homeostasis. ${ }^{18}$ Hence, we used a series of experiments to explore the mechanism of the functional heterogeneity in bile acid reabsorption of cholangiocytes through detecting the expression of bile acid transporters.

Bile acids are absorbed by cholangiocytes lining bile ducts to recycle back to the hepatocytes for re-secretion into bile., ${ }^{9,1920}$ Bile acid transporters expressed in cholangiocytes play an im- portant role in the circulation of bile acids between the cholangiocytes and hepatocytes. ${ }^{18,21,22}$ In this process, ASBT, a bile acid transporter on the apical membrane of cholangiocytes, mediates $\mathrm{Na}^{+}$-dependent bile acids transport, IBABP facilitates bile acids transcellular movement to the basolateral membrane and Ost $\alpha$ is responsible for bile acid efflux from the basolateral membrane. ${ }^{9,18,23,24}$ Further elucidation of the bile acid reabsorption mechanism of bile acid transporters may help understand the functional heterogeneity of cholangiocytes. In the present study, we determined the differences of bile acid transporters expression in small bile ducts and large bile ducts. The results showed that ASBT and IBABP were mainly expressed in large bile ducts, whereas Ost $\alpha$ expression showed no significant difference in small and large bile ducts. Hence, bile acid transporters were distributed heterogeneously in rat bile ducts, which indicated that bile salt reabsorption might mostly occur in the large bile ducts.

In conclusion, the heterogeneous distribution of bile acid transporters in small and large bile ducts may reveal the func- 
tional heterogeneity in bile acid reabsorption of cholangiocytes, and help understand the pathogenesis of various bile duct diseases. Of course, this is just a preliminary study and the role of bile acid transporters in cholangiocytes needs to be determined by further experiments.

\section{CONFLICTS OF INTEREST}

No potential conflict of interest relevant to this article was reported.

\section{ACKNOWLEDGEMENTS}

This study was supported by the National Natural Science Foundation of China (No: 81300280), the Foundation of Health and family planning commission of Sichuan province (No: 16PJ019), and the Youth Foundation of Science and Technology Department of Sichuan Province (2016JQ0023).

\section{AUTHOR CONTRIBUTIONS}

Z.L.L., L. Cheng, and L. Cui performed biological experiments and wrote the manuscript; T.W. and L.J.T. analyzed the data and edited the figures; F.Z.T. and K.X. conceived of the study and participated in the editing of the manuscript.

\section{ORCID}

Long Cheng

https://orcid.org/0000-0003-1240-3360

Tao Wang

https://orcid.org/0000-0002-0005-0994

\section{REFERENCES}

1. Alvaro D, Gigliozzi A, Attili AF. Regulation and deregulation of cholangiocyte proliferation. J Hepatol 2000;33:333-340.

2. Maroni L, Haibo B, Ray D, et al. Functional and structural features of cholangiocytes in health and disease. Cell Mol Gastroenterol Hepatol 2015;1:368-380.

3. Han Y, Glaser S, Meng F, et al. Recent advances in the morphological and functional heterogeneity of the biliary epithelium. Exp Biol Med 2013;238:549-565.

4. Priester S, Wise C, Glaser SS. Involvement of cholangiocyte proliferation in biliary fibrosis. World J Gastrointest Pathophysiol 2010;1:30-37.

5. Benedetti A, Bassotti C, Rapino K, Marucci L, Jezequel AM. A morphometric study of the epithelium lining the rat intrahepatic biliary tree. J Hepatol 1996;24:335-342.

6. Masyuk AI, Masyuk TV, LaRusso NF. Cholangiocyte primary cilia in liver health and disease. Dev Dyn 2008;237:2007-2012.

7. Jung D, York JP, Wang L, et al. FXR-induced secretion of FGF15/19 inhibits CYP27 expression in cholangiocytes through p38 kinase pathway. Pflugers Arch 2014;466:1011-1019.
8. Marin JJ, Macias RI, Briz 0, Banales JM, Monte MJ. Bile acids in physiology, pathology and pharmacology. Curr Drug Metab 2015;17:4-29.

9. Xia X, Francis H, Glaser S, Alpini G, LeSage G. Bile acid interactions with cholangiocytes. World J Gastroenterol 2006;12:35533563.

10. Ferrebee CB, Dawson PA. Metabolic effects of intestinal absorption and enterohepatic cycling of bile acids. Acta Pharm Sin B 2015;5:129-134.

11. Cheng L, Zhao L, Li D, et al. Role of cholangiocyte bile Acid transporters in large bile duct injury after rat liver transplantation. Transplantation 2010;90:127-134.

12. Glaser SS, Gaudio E, Rao A, et al. Morphological and functional heterogeneity of the mouse intrahepatic biliary epithelium. Lab Invest 2009;89:456-469.

13. Hall C, Sato K, Wu N, et al. Regulators of cholangiocyte proliferation. Gene Expr 2017;17:155-171.

14. Sawada R, Ku Y, Akita M, et al. Interleukin-33 overexpression reflects less aggressive tumour features in large-duct type cholangiocarcinomas. Histopathology 2018;73:259-272.

15. Alpini G, Franchitto A, Demorrow S, et al. Activation of alpha(1)adrenergic receptors stimulate the growth of small mouse cholangiocytes via calcium-dependent activation of nuclear factor of activated $\mathrm{T}$ cells 2 and specificity protein 1 . Hepatology 2011;53:628-639.

16. Munoz-Garrido P, Marin JJ, Perugorria MJ, et al. Ursodeoxycholic acid inhibits hepatic cystogenesis in experimental models of polycystic liver disease. J Hepatol 2015;63:952-961.

17. Lozano E, Sanchez-Vicente L, Monte MJ, et al. Cocarcinogenic effects of intrahepatic bile acid accumulation in cholangiocarcinoma development. Mol Cancer Res 2014;12:91-100.

18. Alrefai WA, Gill RK. Bile acid transporters: structure, function, regulation and pathophysiological implications. Pharm Res 2007;24:1803-1823.

19. Camilleri M, Gores GJ. Therapeutic targeting of bile acids. Am J Physiol Gastrointest Liver Physiol 2015;309:G209-G215.

20. Hofmann AF, Hagey LR. Key discoveries in bile acid chemistry and biology and their clinical applications: history of the last eight decades. J Lipid Res 2014;55:1553-1595.

21. Dawson PA. Role of the intestinal bile acid transporters in bile acid and drug disposition. Handb Exp Pharmacol 2011;201:169203.

22. Song P, Rockwell CE, Cui JY, Klaassen CD. Individual bile acids have differential effects on bile acid signaling in mice. Toxicol Appl Pharmacol 2015;283:57-64.

23. Chothe PP, Swaan PW. Resveratrol promotes degradation of the human bile acid transporter ASBT (SLC10A2). Biochem J 2014;459:301-312

24. Schaffner CA, Mwinyi J, Gai Z, Thasler WE, Eloranta JJ, KullakUblick GA. The organic solute transporters alpha and beta are induced by hypoxia in human hepatocytes. Liver Int 2015;35:11521161 